\title{
Top Five Cancer Health Disparities in Florida: Race, Ethnicity, Geographic Location and Socio-Economic Predictors
}

\author{
Matthew Sasaki, Mary Parianos, Saleh Rahman* \\ College of Medicine, University of Central Florida, Orlando, 32827, Florida, United States
}

Received January 12, 2021; Revised February 22, 2021; Accepted March 28, 2021

\section{Cite This Paper in the following Citation Styles}

(a): [1] Matthew Sasaki, Mary Parianos, Saleh Rahman, "Top Five Cancer Health Disparities in Florida: Race, Ethnicity, Geographic Location and Socio-Economic Predictors," Universal Journal of Public Health, Vol. 9, No. 2, pp. 35 - 50, 2021. DOI: 10.13189/ujph.2021.090202.

(b): Matthew Sasaki, Mary Parianos, Saleh Rahman (2021). Top Five Cancer Health Disparities in Florida: Race, Ethnicity, Geographic Location and Socio-Economic Predictors. Universal Journal of Public Health, 9(2), 35 - 50. DOI: 10.13189/ujph.2021.090202.

Copyright $\bigcirc 2021$ by authors, all rights reserved. Authors agree that this article remains permanently open access under the terms of the Creative Commons Attribution License 4.0 International License

\begin{abstract}
Background: In 2019, cancer was found to be the second leading cause of death with an economic cost of over $\$ 90$ billion in the United States. Cancer affects all population groups in the United States; however, certain populations may bear a disproportionate burden of cancer compared with other populations. In this study, we have examined cancer data from 1981-2015 on the top five cancers in Florida for predictors of advanced stages of diagnosis of each cancer. Materials \& Methods: This study is a secondary analysis via data from the Florida Cancer Data System database. The odds for advanced stages of cancer regressed with demographic, insurance, and socioeconomic predictors. Results from the last 34 years and the last 15 years were compared to see the changes during this time. Results: Considerable differences were found in multiple factors for each type of cancer in this study. Most notably, breast cancer yielded a discrepancy for every category, including insurance status, race, and socioeconomic status. In contrast, the least number of identifiable disparities existed with melanoma of the skin. Conclusion: Although many interventions over the past 15 years have been aimed at reducing disparities in cancer outcomes, it appears that social determinants such as race, ethnicity, insurance, income, and geographic location still play a significant role as predictors of the advanced stage of a cancer diagnosis for lung, breast, prostate, colorectal, and melanoma of skin at initial diagnosis for Florida residents.
\end{abstract}

Keywords Florida, Cancer, Health Disparities, Race, Socioeconomic Status, Minority

\section{Introduction}

In 2019, cancer was the second leading cause of death with an economic cost of over $\$ 90$ billion in the United States [1-3]. Cancer affects all population groups in the United States, however, certain populations may bear a disproportionate burden of cancer compared with other populations. According to the National Cancer Institute, disparities exist in several measures of cancer, such as incidence, prevalence, mortality, morbidity, survivorship, burden of cancer, screening rates and stage at diagnosis $[4,5]$. Though cancer disparities are considered due to an interface of culture, socio-economic factors, stress, the environment and biology, members of minority racial and ethnic groups in the United States are affected by multiple factors simultaneously.

Florida ranks second in the nation in newly diagnosed cancer cases and mirrors national trends for the top cancer sites. On average, there are over 115000 new cancers diagnosed and reported annually to the statewide cancer registry, the Florida Cancer Data System [6]. Cancer is the second leading cause of death with over 44000 deaths annually in Florida, and risk factors include tobacco use, 
obesity, and physical inactivity [7]. Of the leading causes of death in Florida, cancer ranks first in terms of years of potential life lost, which surpasses heart disease, stroke and unintentional injuries [8]. Minorities within Florida appear to be affected more so as prior studies have suggested that cancer is the leading cause of death for Hispanics and Afro-Caribbeans [9]. Moreover, cancer constitutes an enormous economic burden on Floridians, resulting in approximately four billion dollars in hospital charges for in-patient hospital care in which cancer is the primary diagnosis [1]. During 2014, nearly $10 \%$ of all hospitalizations that occurred among women listed breast and/or cervical cancer as the underlying cause. Additionally, during 2014, charges due to breast and cervical cancer alone accounted for over $\$ 260$ million in hospital charges $[1,10]$.

Many improvements in health and health outcomes have occurred in recent years; however, there are segments of the United States (US) population that have not seen the same improvements. Minority groups in the USA have worse overall health and often receive lower standards of health care $[11,12]$. This trend also applies to those who have lower incomes, are less educated, and who live in poor neighborhoods [13]. As a popular tourist destination, retiree location, and preferred destination for Central and South American migration, Florida's population is increasing in diversity and continuously changing to represent greater proportions of minorities. For example, South Florida boasts a population of $44 \%$ Hispanics, 32\% Caucasian, and 21\% Black [9]. Thus, it is important to identify the factors potentially contributing to this increased cancer burden.

Although other states have examined these discrepancies, it appears from literature review that Florida does not have the same number of studies examining this topic. This paper aims to fill this gap in the literature, specifically regarding Florida's aging and evolving population. In this study, our aim was to evaluate to what extent disparities in the 1981-2015 data from the Florida Cancer Data System existed. This information was then compared to the 2000-2015 data to determine the extent of improvement in cancer outcome. The five cancers considered for this study, by highest incidence rates, include lung, breast, prostate, colorectal and melanoma of the skin, with the goal of examining the predictors of advanced stages of diagnosis of each cancer. We hypothesize that, like many other states, there has not been significant improvement in solving these healthcare inequities.

\subsection{Lung Cancer}

The CDC reports a higher incidence rate of lung cancer among individuals who live in the eastern half of the United States [14]. States with the highest concentration of new cases in both men and women include Arkansas,
Delaware, Indiana, Kentucky, Maine, Mississippi, Missouri, North Carolina, Ohio, Tennessee, and West Virginia. The American Cancer Society estimates 228150 new cases, and 142670 deaths due to lung cancer in the United States. ${ }^{1}$ In 2015, Florida had 16257 new cases of lung cancer with 11663 reported deaths [6]. In the United States, the number of new cases of lung cancer declined between 1999 and 2015, while the trend for the number of reported deaths reflects a steady decline [14]. During the same period in the state of Florida, the decline in the number of new cases was not as linear. A trend shows a decline in the number of new cases, with plateaus occurring approximately every two years. The White population has the most adverse effects of lung cancer in both the United States and Florida [14,15]. There have been 10530 deaths from lung cancer among White males and females, compared to 943 deaths among Black males and females. [15]

\subsection{Breast Cancer}

Breast cancer is the most diagnosed cancer among women in both developed and developing countries and is the leading cause of cancer-related deaths among women worldwide [1]. An estimated 1676600 women are diagnosed with breast cancer, which accounts for 521900 deaths annually [1]. A diagnosis of breast cancer is responsible for three out of every ten new cases of cancer in women in the United States [8]. Every year in the United States, there are an estimated 271270 new cases of breast cancer, which will lead to 42260 deaths [16]. In 2015, the state of Florida had 15860 new cases of breast cancer with 2816 deaths from breast cancer reported [6]. Considerable differences exist as it pertains to outcomes among minority populations when compared to non-Hispanic White females [4,7,8]. Between 2011 and 2015, Black females had a mortality rate of 29.5 per 100 000 compared to 20.8 deaths per 100000 cases for non-Hispanic White females [16]. In every state, the mortality rate for breast cancer is highest among Black females, and in Florida, the rate is $29 \%$ higher when compared to non-Hispanic White females [16].

\subsection{Prostate Cancer}

Prostate cancer is the second leading diagnosed cancer, while it is the third leading cause of death in the United States [14]. Approximately 1.3 million new cases of prostate cancer are estimated globally [16]. Florida reported 11003 new cases with 2143 deaths in 2015 [6]. 174650 is the estimated number of new cases of prostate cancer within the United States [1]. Over the past 30 years, the trend in new cases of prostate cancer increased significantly in the 1980s and 1990s, which is a result of the screening blood test prostate-specific antigen (PSA). Between 2011 and 2015, an approximate 7\% decrease is 
seen in the number of new cases.

\subsection{Colorectal Cancer}

Colorectal cancer is the fourth leading cancer for new cases, as well as the cause of death in the United States [14]. The American Cancer Society predicts 174650 new cases in the United States in 2019 with 31620 estimated cancer-related deaths [1]. Newly reported cases of colorectal cancer are most concentrated in Alaska, Alabama, Arkansas, Illinois, Iowa, Kentucky, Louisiana, Mississippi, Nebraska, North Dakota, Ohio, and West Virginia. Florida reported 9719 new cases of colorectal cancer in 2015, making it the fourth leading cancer diagnosed in the state, with 3634 associated deaths [6]. Globally, an estimated 1.8 new cases were estimated by the American Cancer Society [16]. The populations with the highest number of new cases of colorectal cancer in the United States are White, Black, and Hispanic [14]. Between 1999 and 2015, the trend in the United States, as well as in Florida, reflects a steady decline in the number of new cases and deaths being reported.

\subsection{Melanoma of the Skin}

Melanoma of the skin is among the top ten cancers with new cases reported in the United States, estimated at 96 480 new cases per year with 7230 related deaths [14]. In Florida, 6183 new cases of melanoma were reported in 2015, while 717 deaths were reported [6]. The incidence trend for melanoma in the United States has increased significantly over the past 30 years [1]. Trends in new cases of melanoma in Florida are reflective of the national trend, and over the last several years, the number of reported cases steadily increased with 8360 expected cases this year [14]. Across all races, the White and Hispanic populations are most adversely affected by melanoma [14]. In 2015, 497 deaths were reported for White males in Florida, with 220 reported deaths of White females [10]. The five-year survival of melanoma is approximately the same across all races and both sexes within the United States [14].

\section{Methods}

This study is a secondary analysis of data obtained from the Florida Cancer Data System (FCDS) database. This is a statewide database for the state of Florida and is part of the CDC's National Program of Cancer Registries. The FCDS acquires cancer incidence information from over 250 hospitals and facilities licensed in the state of Florida, resulting in approximately 115000 cases each year. Reporting requirements include information regarding cancer diagnosis, stage at diagnosis, medical history, tissue diagnosis, treatment, method of diagnosis, and laboratory data. All submitted cases are reviewed according to the CDC's National Program of Cancer Registries standards. Any duplicate cases are removed and the database is updated annually. The FCDS also provides mortality data. The data received for this study was de-identified and private.

The FCDS categorized each cancer's grade based on the International Classification of Diseases for Oncology (ICD-O-3) guidelines. There are 4 different grades which are used to describe how closely a tumor resembles its tissue of origin. Grade one is considered any malignant cancer that is well-differentiated or differentiated not otherwise specified. Grade two is any malignant cancer that is moderately differentiated, moderately well-differentiated, or of intermediate differentiation. Grade three is any malignant cancer that is poorly differentiated. Grade four is any malignant cancer that is undifferentiated or anaplastic [17].

The participants for this retrospective data analysis included patients that were diagnosed in one of Florida's 67 counties between the years 1981-2015 with lung cancer, breast cancer, prostate cancer, colorectal cancer, or melanoma of skin. These cancers were chosen for their incidence rates and, as a result, were determined to be the top five cancers of concern at this time. This study then classified each participant's cancer as either "low-grade" or "high-grade" based on their ICD-O-3 grade. Cancers with ICD-O-3 grades one and two were grouped as "low-grade". Cancers with ICD-O-3 grades three and four were grouped as "high-grade". Individuals with cancers classified as null cell, NK cell, unknown, or those not meeting criteria for ICD-O-3 grading classification were excluded from this study's statistical analysis.

This study calculated odd ratios to analyze the association between variables with a significance level determined to be $P<0.05$ and $95 \%$ confidence interval. The predictor variables for this study include insurance status, race, ethnicity, gender, marital status, urban-rural classification, and community economic status.

The FCDS database provided data on race, ethnicity, gender, and marital status. Other variables studied include county at diagnosis and insurance status. The Florida counties were classified as rural or urban based on their classification in the 2010 US census. A county was also considered rural if it contained less than 100 people per square mile. Insurance status was categorized by individuals with insurance and individuals without insurance. For the individuals with insurance, the insurance categories available from FCDS information include private insurance, Medicaid, Medicare, and Military/Tricare.

Community Economic Status (CES) is a variable that is measured by median income per zip code and was studied in one of America's largest surveillance projects in Colorado [18]. The study specifically considered these socioeconomic factors in relation to screenings for breast 
cancer, and income was found to be a predictor of mammography adherence behavior. Further studies using similar concepts also found an association with community economic status measured by median income, number of modes of transportation per household, and percentage of households with or without vehicles [19].

\section{Results}

\subsection{Lung Cancer}

Lung cancer remains the leading cause of cancer death. The socioeconomic factors analyzed in this study from 1981-2015 and the odds ratios from the data are presented in table one below. The study population recorded for lung cancer from 1981-2015 consisted of 492886 total observations. However, only 150229 were used for analysis. The results demonstrated multiple factors that considerably influenced the odds of being diagnosed with advanced stage lung cancer. Those who were uninsured from 1981-2015 were $46.9 \%$ more likely to have been diagnosed with a high grade of lung cancer at initial diagnosis compared to those with insurance $(\mathrm{OR}=1.47$, 95\% CI $=1.38-1.56)$. Compared to African Americans, Caucasians were $6.8 \%$ more likely to be diagnosed with advanced lung cancer $(\mathrm{OR}=1.07,95 \% \mathrm{CI}=1.02-1.11)$. However, Caucasians were $29 \%$ less likely to be diagnosed with advanced lung cancer at initial diagnosis compared to other races $(\mathrm{OR}=0.71,95 \% \mathrm{CI}=0.64-0.79)$. Men were $27 \%$ more likely to be diagnosed with an advanced grade of lung cancer compared to women $(\mathrm{OR}=$ $1.27,95 \% \mathrm{CI}=1.24-1.29)$, while being single appeared to be a protective factor $(\mathrm{OR}=0.91,95 \% \mathrm{CI}=0.89-0.93)$. Ethnicity did not appear to be an influencing factor for lung cancer grade. Living in a rural county provided a protective factor from being diagnosed with advanced lung cancer compared to urban counties $(\mathrm{OR}=0.93,95 \%$ $\mathrm{CI}=0.91-0.96)$. However, compared to those with a median income $>\$ 46000$, those with a median income of $<\$ 35000$ and an income of \$35 001- \$45 999 were 15\% and $22 \%$ more likely to be diagnosed with advanced lung cancer, respectively $(\mathrm{OR}=1.15,95 \% \mathrm{CI}=1.08-1.22 ; \mathrm{OR}$ $=1.22,95 \% \mathrm{CI}=1.19-1.25)$.

Looking at the 15-year period of 2000-2015 alone, there were 321865 total observations in this study, however, only 143713 were included for analysis (Table 2). The 15-year period of analysis showed similar trends to the 34-year period with the results as follows. Ethnicity did not appear to be an influencing factor for cancer grade at diagnosis. The odds of being diagnosed with advanced lung cancer for uninsured individuals was 1.47 compared to those with insurance $(95 \% \mathrm{CI}=1.38-1.56)$. Caucasians were 1.06 and 0.72 times as likely to have advanced lung cancer compared to African Americans and other races, respectively $(95 \% \mathrm{CI}=1.02-1.58 ; 95 \% \mathrm{CI}=0.65-0.81)$. With regards to gender, males were $28 \%$ more likely to be diagnosed with advanced lung cancer $(\mathrm{OR}=1.28,95 \% \mathrm{CI}$ $=1.25-1.30)$. Being single proved to be a protective factor compared to those that were married (OR $=0.91,95 \% \mathrm{CI}$ $=0.89-0.93)$. Those living in rural counties were $6 \%$ less likely to be diagnosed with advanced lung cancer compared to those living in urban counties $(\mathrm{OR}=0.94$, $95 \% \mathrm{CI}=0.91-0.96)$. Income again played a considerable role in lung cancer grade. Compared to those with a median income $>\$ 46000$, those with an income $<\$ 35000$ were $62 \%$ more likely to be diagnosed with advanced lung cancer $(\mathrm{OR}=1.62,95 \% \mathrm{CI}=1.09-1.24)$ and individuals with a median income between $\$ 35001-\$ 45$ 999 were $23 \%$ more likely $(\mathrm{OR}=1.23,95 \% \mathrm{CI}=$ 1.20-1.25).

For lung cancer, the odds of being diagnosed with an advanced grade of cancer for White versus Black populations within those last 15 years decreased approximately $1 \%$ (Figure 1). Additionally, there is no change in the odds ratio over these time periods when considering the Hispanic population with the non-Hispanic population and males compared to females. However, odds increased among less than \$35 000 income and \$35000 - \$46000 income compared to \$46 000 or more income group (54\% and $20 \%$ respectively). The difference between insured and uninsured remained unchanged. 
Table 1. ORs based on the last 34 years of data for lung cancer Odds ratio estimates for advanced lung cancer, 1981-2015 $\mathrm{N}=492886, \mathrm{n}=150229$

\begin{tabular}{|c|c|c|c|}
\hline \multicolumn{4}{|c|}{$\begin{array}{l}\text { Odds ratio estimates for advanced lung cancer, 1981-2015 } \\
\qquad \mathrm{N}=492886, \mathrm{n}=150229\end{array}$} \\
\hline Variables & Odds ratio & \multicolumn{2}{|c|}{$95 \%$ Confidence level } \\
\hline Uninsured $\mathrm{v}$ insured & 1.47 & 1.38 & $1.56^{*}$ \\
\hline White v Black & 1.07 & 1.02 & $1.11 *$ \\
\hline Single v married & 0.91 & 0.89 & $0.93 *$ \\
\hline Hispanic v Non-Hispanic & 1.02 & 0.98 & 1.07 \\
\hline Rural v Urban & 0.93 & 0.91 & $0.96 *$ \\
\hline$\geq \$ 46000 \mathrm{v}<\$ 35000$ & 1.15 & 1.08 & $1.22 *$ \\
\hline
\end{tabular}

Asterisk indicates $P$ value $<0.05$.

Table 2. ORs based on the last 15 years of data for lung cancer Odds ratio estimates for advanced lung cancer, 2000-2015

\begin{tabular}{|c|c|c|c|}
\hline \multicolumn{4}{|c|}{$\begin{array}{l}\text { Odds ratio estimates for advanced lung cancer, 2000-2015 } \\
\qquad \mathrm{N}=321865, \mathrm{n}=143713\end{array}$} \\
\hline \multirow{2}{*}{ Variables } & \multirow{2}{*}{ Odds ratio } & \multicolumn{2}{|c|}{$95 \%$ Confidence level } \\
\hline & & Lower boundary & Lower boundary \\
\hline Uninsured $\mathrm{v}$ insured & 1.47 & 1.38 & $1.56^{*}$ \\
\hline White v Black & 1.06 & 1.02 & $1.58 *$ \\
\hline Single v married & 0.91 & 0.89 & $0.93 *$ \\
\hline Hispanic v Non-Hispanic & 1.02 & 0.98 & 1.07 \\
\hline Rural v Urban & 0.94 & 0.91 & $0.96 *$ \\
\hline$\geq \$ 46000 \mathrm{v}<\$ 35000$ & 1.62 & 1.09 & $1.24 *$ \\
\hline
\end{tabular}

Asterisk indicates $P$ value $<0.05$.

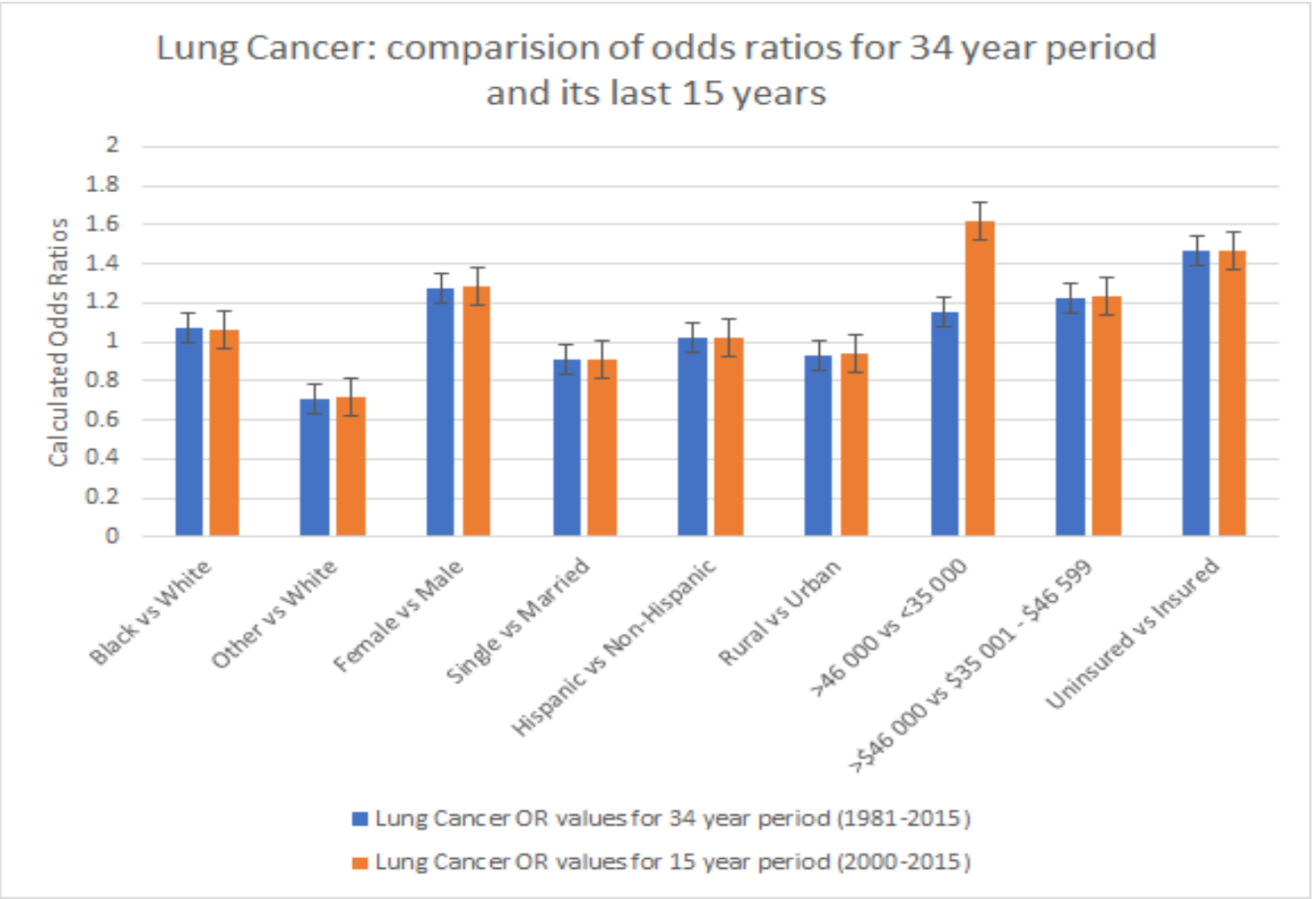

Figure 1. Comparison of ORs over 34 years (1981-2015, blue) versus 15 years (2000-2015, orange) data for lung cancer. X-axis indicating the socioeconomic factor, and the Y-axis indicating the OR value. As seen above, there have not been significant changes in ORs for each socioeconomic factor analyzed when comparing 2000-2015 to 1981-2015. 


\subsection{Breast Cancer}

Socioeconomic factors also played a considerable role in having advanced breast cancer at initial diagnosis as demonstrated in tables 3 and 4 . Table 3 demonstrates the odds ratios for influencing factors on grade of breast cancer from 1981-2015. Over this time period, there were a total of 486899 cases, and 250460 were included in the analysis. Compared to insured individuals, uninsured individuals were $50 \%$ more likely to be diagnosed with advanced breast cancer $(\mathrm{OR}=1.50,95 \% \mathrm{CI}=1.44-1.57)$. Race also had an impact as African Americans and other races were $98 \%$ and $17 \%$ more likely to have advanced breast cancer at initial diagnosis compared to Caucasian individuals, respectively $(\mathrm{OR}=1.98,95 \% \mathrm{CI}=1.93-$ $2.03 ; \mathrm{OR}=1.17,95 \% \mathrm{CI}=1.10-1.24$, respectively). Unlike lung cancer, single individuals were 1.03 times as likely to be diagnosed with advanced breast cancer compared to married individuals $(95 \% \mathrm{CI}=1.01-1.05)$. The odds of being diagnosed with advanced breast cancer for Hispanic individuals was 0.85 compared to non-Hispanic individuals $(95 \% \mathrm{CI}=0.83-0.88)$. Those living in rural counties are 1.04 times as likely to have advanced breast cancer at initial diagnosis compared to those living in urban counties (95\% CI $=1.02-1.06)$. Income also appeared to also play a role. Compared to those with an income $>\$ 46000$, individuals making $<\$ 35$ 000 were 1.14 times as likely $(95 \% \mathrm{CI}=1.08-1.20)$ and those with an income between $\$ 35001$ - $\$ 45999$ were 1.02 times as likely to be diagnosed with advanced breast cancer $(95 \% \mathrm{CI}=1.00-1.04)$.

From 2000-2015, insurance status, race, marriage status, ethnicity, residence, and income were all factors that had an effect on diagnosis with advanced breast cancer (Table 4). The 15-year period of analysis (2000-2015) showed similar trends to the 34 -year period with the results as follows. During this time, there were 334585 total cases, and 224054 were used for analysis. Uninsured individuals were 1.49 times as likely to be diagnosed with advanced breast cancer compared to insured individuals (95\% CI $=1.42-1.55)$. With regards to race, African Americans were $99 \%$ and other races were $18 \%$ more likely to have advanced breast cancer compared to Caucasians (95\% CI $=1.93-2.04 ; 95 \% \mathrm{CI}=1.11-1.25$, respectively). Compared to married individuals, the odds of being diagnosed with advanced breast cancer in single individuals was 1.03 (95\% CI $=1.01-1.05)$. Again, being of Hispanic descent appeared to be a protective factor $(\mathrm{OR}=0.85,95 \% \mathrm{CI}=0.82-0.87)$. Living in a rural county appeared to increase the odds of having advanced breast cancer at first diagnosis $(\mathrm{OR}=1.04,95 \% \mathrm{CI}=1.02-1.06)$. Also, those with an income $<\$ 35000$ or $\$ 35001-\$ 45$ $999(\mathrm{OR}=1.13,95 \% \mathrm{CI}=1.07-1.19 ; \mathrm{OR}=1.02,95 \% \mathrm{CI}$ $=1.00-1.04$, respectively) had increased odds of being diagnosed with advanced breast cancer compared to those with an income $>\$ 46000$.

For breast cancer, the odds of being diagnosed with an advanced grade of cancer for the Black population are higher in both in the 34-year period and in its last 15 years compared to its White counterpart with an OR 1.98 versus 1.93 , respectively (decreased approximately $5 \%$ ). Similar to lung cancer, there is no change in the odds ratio with comparison of the Hispanic population and non-Hispanic population and males compared to females. The difference between insured and uninsured populations remained unchanged. However, the odds have increased among the $<\$ 35000$ income group and the $\$ 35000$ - $\$ 46$ 000 income group to be diagnosed with an advanced stage of breast cancer at initial diagnosis compared to the $\$ 46$ 000 or more income group (54\% and $20 \%$, respectively). These comparisons can be seen in Figure 2.

Table 3. ORs based on the last 34 years of data for breast cancer

\begin{tabular}{|c|c|c|c|}
\hline \multicolumn{4}{|c|}{$\begin{array}{l}\text { Odds ratio estimates for advanced breast cancer, 1981-2015 } \\
\qquad \mathrm{N}=486899, \mathrm{n}=250460\end{array}$} \\
\hline \multirow{2}{*}{ Variables } & \multirow{2}{*}{ Odds ratio } & \multicolumn{2}{|c|}{$95 \%$ Confidence level } \\
\hline & & Lower boundary & Lower boundary \\
\hline Uninsured $\mathrm{v}$ insured & 1.50 & 1.44 & $1.57 *$ \\
\hline White v Black & 1.98 & 1.93 & $2.03 *$ \\
\hline White v other & 1.17 & 1.10 & $1.24 *$ \\
\hline Female v male & 1.03 & 1.01 & $1.05 *$ \\
\hline Single v married & 0.85 & 0.83 & $0.88^{*}$ \\
\hline Hispanic v Non-Hispanic & 1.04 & 1.02 & $1.06^{*}$ \\
\hline Rural v Urban & 1.14 & 1.08 & $1.20 *$ \\
\hline$\geq \$ 46000 \mathrm{v}<\$ 35000$ & 1.02 & 1.00 & $1.04 *$ \\
\hline
\end{tabular}

Asterisk indicates $P$ value $<0.05$. 
Table 4. ORs based on the last 15 years of data for breast cancer

\begin{tabular}{|c|c|c|c|}
\hline \multicolumn{2}{|c|}{$\begin{array}{l}\text { Odds ratio estimates for advanced breast cancer, 2000-2015 } \\
\mathrm{N}=334585, \mathrm{n}=224054\end{array}$} \\
\hline \multirow{2}{*}{ Variables } & \multirow{2}{*}{ Odds ratio } & \multicolumn{2}{c|}{$95 \%$ Confidence level } \\
\cline { 3 - 4 } & & Lower boundary & Lower boundary \\
\hline Uninsured v insured & 1.49 & 1.42 & $1.55^{*}$ \\
\hline White v Black & 1.99 & 1.93 & $2.04^{*}$ \\
\hline White v other & 1.18 & 1.11 & $1.25^{*}$ \\
\hline Female v male & 1.03 & 1.01 & $1.05^{*}$ \\
\hline Single v married & 0.85 & 0.82 & $0.87^{*}$ \\
\hline Hispanic v Non-Hispanic & 1.04 & 1.02 & $1.06^{*}$ \\
\hline Rural v Urban & 1.13 & 1.07 & $1.19^{*}$ \\
\hline$\geq \$ 4600 \mathrm{v}<\$ 35000$ & 1.02 & 1.00 & $1.04^{*}$ \\
\hline
\end{tabular}

Asterisk indicates $P$ value $<0.05$.

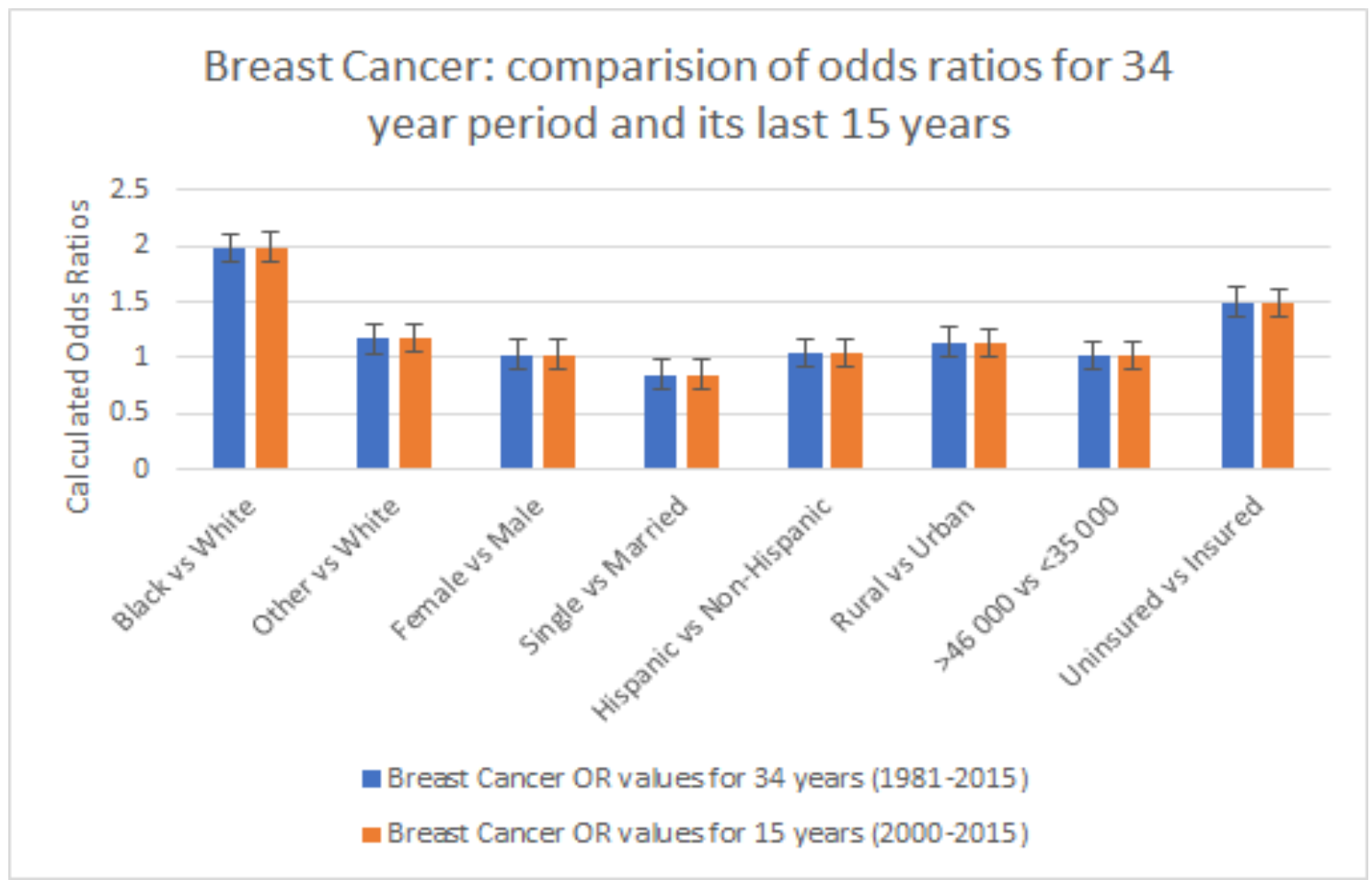

Figure 2. Comparison of ORs over 34 years (1981-2015, blue) versus 15 years (2000-2015, orange) data for breast cancer. X-axis indicating the socioeconomic factor, and the Y-axis indicating the OR value. As seen above, there have not been significant changes in ORs for each socioeconomic factor analyzed when comparing 2000-2015 to 1981-2015.

\subsection{Prostate Cancer}

There were a total of 423973 cases of prostate cancer between 1981-2015, and 226924 were included in this analysis (table five). Unlike lung and breast cancer, median income did not appear to be an influencing factor for diagnosis of advanced prostate cancer. Compared to those with insurance, uninsured individuals were 39\% more likely to be diagnosed with advanced prostate cancer $(\mathrm{OR}=1.39,95 \% \mathrm{CI}=1.30-1.47)$. Caucasians were 1.12 times as likely compared to African Americans (95\% $\mathrm{CI}=1.09-1.14)$ and 1.23 times as likely compared to other races $(95 \% \mathrm{CI}=1.14-1.33)$ to be diagnosed with advanced prostate cancer. Being single appeared to be a protective factor $(\mathrm{OR}=0.86,95 \% \mathrm{CI}=0.84-0.88)$, while those of Hispanic descent were 1.06 times as likely to have advanced prostate cancer at initial diagnosis $(\mathrm{OR}=$ $1.06,95 \% \mathrm{CI}=1.03-1.09)$. The odds of being diagnosed with advanced prostate cancer for individuals living in rural counties were 1.10 compared to those living in urban counties $(95 \% \mathrm{CI}=1.08-1.13)$.

During the 15-year period from 2000-2015, the FCDS had 274812 total cases of prostate cancer, but only 216 250 were included in this analysis. The 15 -year period of analysis (Table 6) showed similar trends to the 34-year period with the results as follows. The median income did not appear to particularly impact the odds of being diagnosed with advanced prostate cancer. However, those without insurance were 1.38 times as likely to be diagnosed with advanced prostate cancer compared to 
insured individuals $(95 \% \mathrm{CI}=1.30-1.47)$. Compared to African Americans and other races, Caucasians are 1.11 $(95 \% \mathrm{CI}=1.08-1.14)$ and $1.22(95 \% \mathrm{CI}=1.13-1.32)$ times as likely to have been diagnosed with advanced prostate cancer at initial diagnosis, respectively. Single status is again a protective factor for being diagnosed with prostate cancer $(\mathrm{OR}=0.86,95 \% \mathrm{CI}=0.84-0.88)$. Hispanic individuals were $7 \%$ more likely to have advanced prostate cancer at initial diagnosis $(\mathrm{OR}=1.07$, $95 \% \mathrm{CI}=1.04-1.10)$. Compared to living in an urban county, rural county residents were $11 \%$ more likely to be diagnosed with advanced prostate cancer $(\mathrm{OR}=1.11$,
$95 \% \mathrm{CI}=1.08-1.13)$.

Figure 3 shows the odds of being diagnosed with an advanced grade of prostate cancer for insured versus uninsured, White versus Black populations, and White versus other populations decreased approximately $1 \%$ within the last 15 years compared to the prior 34 years. In contrast, the odds of being diagnosed with an advanced grade of cancer increased by $1 \%$ over the last 15 years for single versus married, non-Hispanic versus Hispanic, and urban versus rural populations. There was no change over the last 15 years with regards to income or gender.

Table 5. ORs based on the last 34 years of data for prostate cancer

\begin{tabular}{|c|c|c|c|}
\hline \multicolumn{2}{|c|}{$\begin{array}{c}\text { Odds ratio estimates for advanced prostate cancer, 1981-2015 } \\
\mathrm{N}=423\end{array}$ 973, $\mathrm{n}=226924$} \\
\hline Variables & \multirow{2}{*}{ Odds ratio } & \multicolumn{2}{c|}{$95 \%$ Confidence level } \\
\cline { 3 - 4 } & & Lower boundary & Lower boundary \\
\hline Uninsured v insured & 1.39 & 1.30 & $1.47^{*}$ \\
\hline White v Black & 1.12 & 1.09 & $1.14^{*}$ \\
\hline White v other & 1.23 & 1.14 & $1.33^{*}$ \\
\hline Single v married & 0.86 & 0.84 & $0.88^{*}$ \\
\hline Hispanic v Non-Hispanic & 1.06 & 1.03 & $1.09^{*}$ \\
\hline Rural v Urban & 1.04 & 0.98 & 1.10 \\
\hline$\geq \$ 46000 \quad \mathrm{v}<\$ 35000$ & 1.01 & 0.99 & 1.03 \\
\hline
\end{tabular}

Asterisk indicates $P$ value $<0.05$.

Table 6. ORs based on the last 15 years of data for prostate cancer

\begin{tabular}{|c|c|c|c|}
\hline \multicolumn{2}{|c|}{$\begin{array}{c}\text { Odds ratio estimates for advanced prostate cancer, 2000-2015 } \\
\mathrm{N}=274, \mathrm{n}=216250\end{array}$} \\
\hline Variables & \multirow{2}{*}{ Odds ratio } & \multicolumn{2}{c|}{$95 \%$ Confidence level } \\
\cline { 3 - 4 } & & Lower boundary & Lower boundary \\
\hline Uninsured v insured & 1.38 & 1.30 & $1.47^{*}$ \\
\hline White v Black & 1.11 & 1.08 & $1.14^{*}$ \\
\hline White v other & 1.22 & 1.13 & $1.32^{*}$ \\
\hline Single v married & 0.86 & 0.84 & $0.88^{*}$ \\
\hline Hispanic v Non-Hispanic & 1.07 & 1.04 & $1.10^{*}$ \\
\hline Rural v Urban & 1.05 & 0.99 & 1.11 \\
\hline$\geq \$ 46000 \quad \mathrm{v}<\$ 35000$ & 1.01 & 0.99 & 1.03 \\
\hline
\end{tabular}

Asterisk indicates $P$ value $<0.05$. 


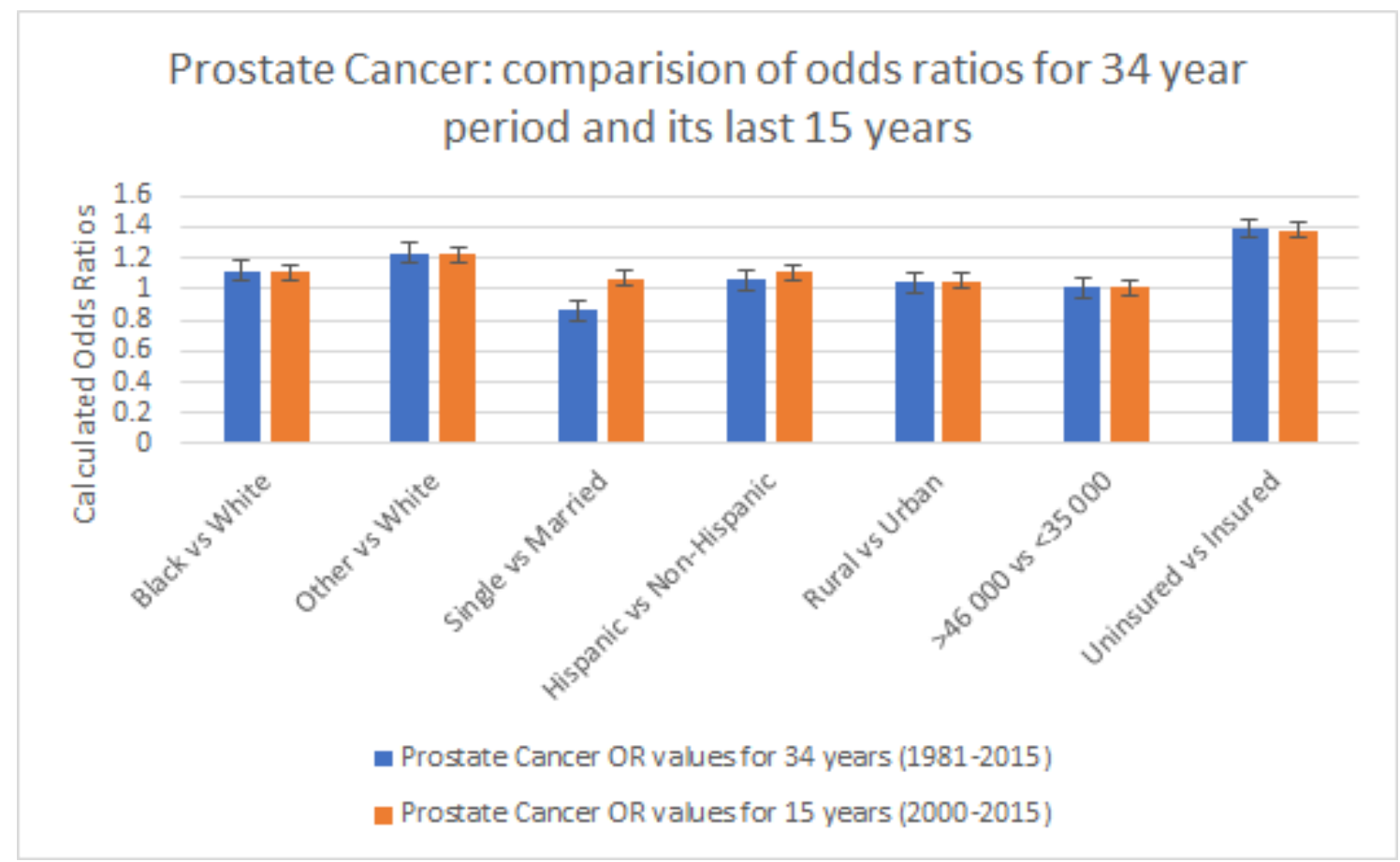

Figure 3. Comparison of ORs over 34 years (1981-2015, blue) versus 15 years (2000-2015, orange) data for Prostate. X-axis indicating the socioeconomic factor, and the Y-axis indicating the OR value. As seen above, there have not been significant changes in ORs for each socioeconomic factor analyzed when comparing 2000-2015 to 1981-2015.

\subsection{Colorectal Cancer}

According to the FCDS database, there were 370329 total cases of colorectal cancer over the 34-year period from 1981-2015, and 167649 were included in this study as shown below in table seven. Uninsured individuals were $15 \%$ more likely to have advanced colorectal cancer at diagnosis compared to insured individuals $(\mathrm{OR}=1.15$, $95 \% \mathrm{CI}=1.07-1.22$ ). Caucasians were $12 \%$ less likely to be diagnosed with advanced colorectal cancer compared to African Americans ( $\mathrm{OR}=0.88,95 \% \mathrm{CI}=0.84-0.92)$, but there was not a distinct association observed between Caucasians and other races. Compared to women, men were $17 \%$ less likely to have advanced colorectal cancer at first diagnosis $(\mathrm{OR}=0.83,95 \% \mathrm{CI}=0.81-0.85)$. The odds of being diagnosed with advanced colorectal cancer for single individuals were 0.95 compared to married individuals $(95 \% \mathrm{CI}=0.93-0.97)$. Hispanic individuals were 1.08 times as likely as non-Hispanic individuals to be diagnosed with advanced colorectal cancer $(\mathrm{OR}=1.08$, $95 \% \mathrm{CI}=1.04-1.12$ ). Whether individuals lived in a rural or urban county did not appear to be an influencing factor. Compared to individuals with a median income $>\$ 46000$, those making \$35001 - \$45999 were 7\% more likely to be diagnosed with advanced colorectal cancer $(\mathrm{OR}=1.07$, $95 \% \mathrm{CI}=1.04-1.10)$. There was no considerable change in odds when comparing those with an income $<\$ 35000$ and $>\$ 46000$.

From 2000-2015, the FCDS recorded 221801 total cases of colorectal cancer, and 159404 cases were included in this analysis. The 15-year period of analysis
(Table 8) showed similar trends to the 34-year period with the results as follows. Compared to those with insurance, uninsured individuals were 1.14 as likely to have advanced colorectal cancer at initial diagnosis. Caucasians had lower odds of having advanced colorectal cancer compared to African Americans $(\mathrm{OR}=0.88,95 \% \mathrm{CI}=$ 0.84-0.92). However, there wasn't a notable difference in odds when comparing Caucasians and other races. Males also were $17 \%$ less likely to have advanced colorectal cancer on initial diagnosis $(\mathrm{OR}=0.83,95 \% \mathrm{CI}=$ 0.81-0.85). Being single appears to be a protective factor as well $(\mathrm{OR}=0.94,95 \% \mathrm{CI}=0.92-0.97)$. Those of Hispanic ethnicity were 1.07 times as likely as non-Hispanic individuals to be diagnosed with advanced colorectal cancer $(\mathrm{OR}=1.07,95 \% \mathrm{CI}=1.03-1.11)$. There was no notable relationship when comparing individuals that lived in a rural area compared to an urban county. Those with a median income between \$35 001-\$45 999 were $6 \%$ more likely to develop advanced colorectal cancer at diagnosis compared to those with a median income $>\$ 46000(\mathrm{OR}=1.06,95 \%=1.04-1.09)$. Incomes $<\$ 35000$ and $>\$ 46000$ did not appear to be influencing factors.

When considering trends between the 34-year period and 15 -year period for colorectal cancer, there is a $1 \%$ decrease in advanced forms of cancer noted for insurance status, Hispanic ethnicity, and income and a $1 \%$ increase in advanced forms of cancer noted for marital status. Overall, there was negligible change over the last 34 years (Figure 4). 
Table 7. ORs based on the last 34 years of data for colorectal cancer

\begin{tabular}{|c|c|c|c|}
\hline \multicolumn{4}{|c|}{$\begin{array}{l}\text { Odds ratio estimates for advanced colorectal cancer, 1981-2015 } \\
\qquad \mathrm{N}=370329, \mathrm{n}=167649\end{array}$} \\
\hline \multirow{2}{*}{ Variables } & \multirow{2}{*}{ Odds ratio } & \multicolumn{2}{|c|}{$95 \%$ Confidence level } \\
\hline & & Lower boundary & Lower boundary \\
\hline Uninsured $\mathrm{v}$ insured & 1.15 & 1.07 & $1.22 *$ \\
\hline White v Black & 0.88 & 0.84 & $0.92 *$ \\
\hline White v other & 0.92 & 0.82 & 1.03 \\
\hline Female v male & 0.83 & 0.81 & $0.85^{*}$ \\
\hline Single v married & 0.95 & 0.93 & $0.97 *$ \\
\hline Hispanic v Non-Hispanic & 1.08 & 1.04 & $1.12 *$ \\
\hline Rural v Urban & 1.02 & 0.99 & 1.06 \\
\hline$\geq \$ 46000 \mathrm{v}<\$ 35000$ & 0.97 & 0.90 & 1.04 \\
\hline $\begin{array}{c}\geq \$ 46000 \mathrm{v} \\
\$ 35001-\$ 45999\end{array}$ & 1.07 & 1.04 & $1.10^{*}$ \\
\hline
\end{tabular}

Asterisk indicates $P$ value $<0.05$.

Table 8. ORs based on the last 15 years of data for colorectal cancer

\begin{tabular}{|c|c|c|c|}
\hline \multicolumn{4}{|c|}{$\begin{array}{l}\text { Odds ratio estimates for advanced colorectal cancer, 2000-2015 } \\
\qquad \mathrm{N}=221801, \mathrm{n}=159404\end{array}$} \\
\hline Variables & Odds ratio & \multicolumn{2}{|c|}{$95 \%$ Confidence level } \\
\hline Uninsured $\mathrm{v}$ insured & 1.14 & 1.07 & $1.22 *$ \\
\hline White v Black & 0.88 & 0.84 & $0.92 *$ \\
\hline Single v married & 0.94 & 0.92 & $0.97 *$ \\
\hline Hispanic v Non-Hispanic & 1.07 & 1.03 & $1.11^{*}$ \\
\hline Rural v Urban & 1.02 & 0.99 & 1.05 \\
\hline$\geq \$ 46000 \mathrm{v}<\$ 35000$ & 0.96 & 0.88 & 1.03 \\
\hline
\end{tabular}

Asterisk indicates $P$ value $<0.05$.

\section{Colorectal Cancer: comparision of odds ratios for 34 year period and its last 15 years}

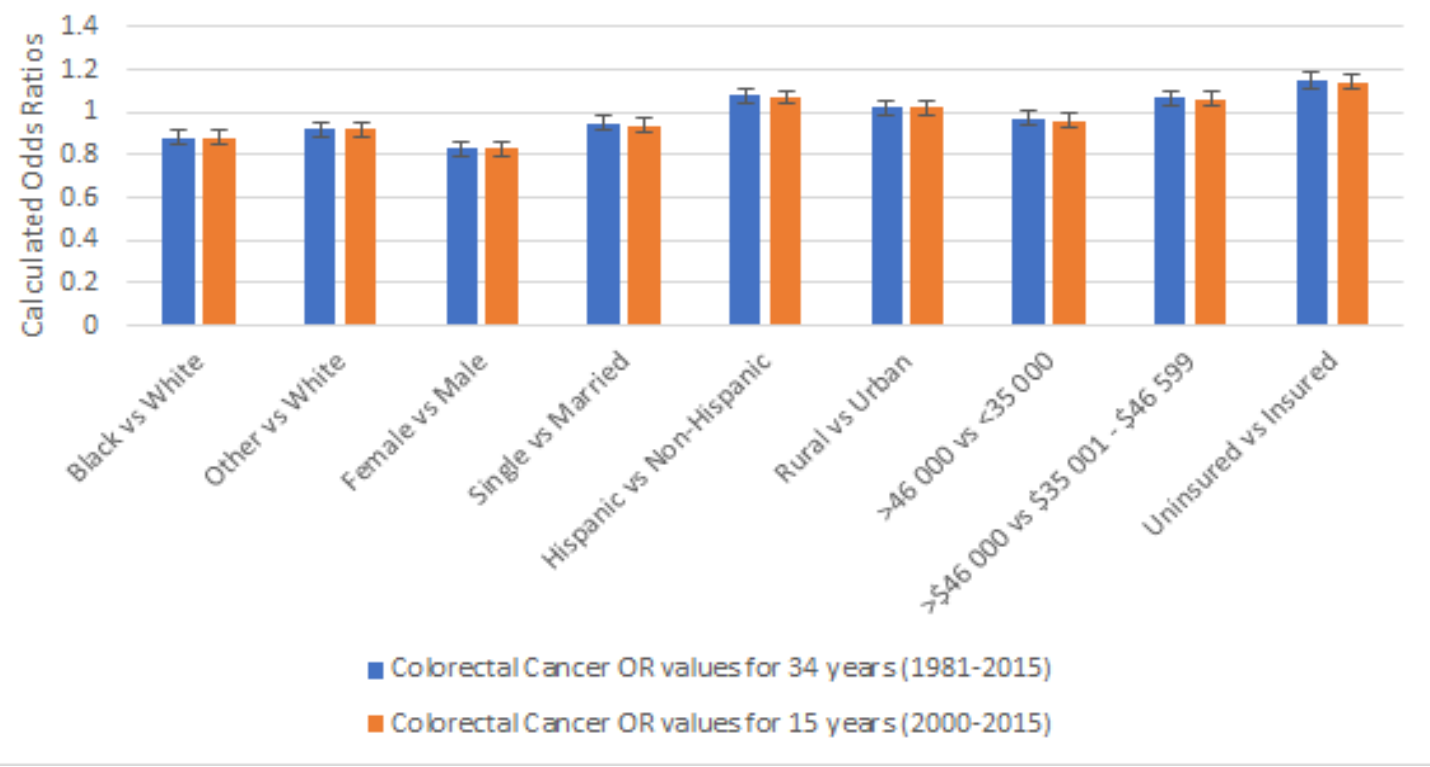

Figure 4. Comparison of ORs over 34 years (1981-2015, blue) versus 15 years (2000-2015, orange) data for colorectal cancer. X-axis indicating the socioeconomic factor, and the $\mathrm{Y}$-axis indicating the OR value. As seen above, there have not been significant changes in ORs for each socioeconomic factor analyzed when comparing 2000-2015 to 1981-2015. 


\subsection{Melanoma of the Skin}

From 1981-2015, the FCDS recorded a total of 162864 cases of melanoma, and 1130 cases were used in this analysis (Table 9). Although odds ratios were increased for having advanced melanoma of the skin at initial diagnosis in uninsured individuals $(\mathrm{OR}=1.54)$, the values for African Americans compared to Caucasians ( $\mathrm{OR}=$ $2.46)$, males $(\mathrm{OR}=1.14)$, Hispanics $(\mathrm{OR}=1.04)$, those living in rural areas $(\mathrm{OR}=1.06)$, and those with a median income between $\$ 35001$ - $\$ 45999$ compared to > $\$ 46000$ $(\mathrm{OR}=1.15)$ did not appear to be influencing factors.

There were a total of 135765 cases of melanoma from 2000-2015, and 1077 cases were used for the analysis in Table 10. The 15-year period of analysis (2000-2015) showed similar trends to the 34-year period with the results as follows. While the odds ratios were increased for having advanced melanoma at initial diagnosis for uninsured individuals over this 15 -year period $(\mathrm{OR}=$
1.51), the values for African Americans compared to Caucasians $(\mathrm{OR}=2.53)$, males $(\mathrm{OR}=1.16)$, Hispanics $(\mathrm{OR}=1.12)$, individuals living in rural areas $(\mathrm{OR}=1.06)$, and individuals with a median income between $\$ 35001$ $\$ 45999$ compared to $>\$ 46000(\mathrm{OR}=1.15)$ did not present notable findings.

Figure 5 shows that the odds of being diagnosed with an advanced grade of cancer for over the last 15 years decreased by $3 \%$ for insured versus uninsured and decreased by $1 \%$ for single versus married. The odds of being diagnosed with an advanced grade of cancer increased over the last 15 years by $7 \%$ for White versus Black, $2 \%$ for female versus male, $8 \%$ for non-Hispanic versus Hispanic, and 3\% for income $>\$ 46,000$ versus $<\$ 35,000$. There was no change for neither White versus other populations nor urban versus rural. The comparisons for each of these aspects with all five cancers can be noted in Figure 6.

Table 9. ORs based on the last 34 years of data for melanoma

\begin{tabular}{|c|c|c|c|}
\hline \multicolumn{2}{|c|}{$\begin{array}{c}\text { Odds ratio estimates for advanced melanoma, 1981-2015 } \\
\mathrm{N}=162864 \mathrm{n}=1130\end{array}$} \\
\hline \multirow{2}{*}{ Variables } & \multirow{2}{*}{ Odds ratio } & \multicolumn{2}{c|}{$95 \%$ Confidence level } \\
\cline { 3 - 4 } & & Lower boundary & Lower boundary \\
\hline Uninsured v insured & 1.54 & 0.75 & 3.15 \\
\hline White v Black & 2.46 & 0.79 & 7.64 \\
\hline White v other & 0.37 & 0.07 & 2.03 \\
\hline Female v male & 1.14 & 0.89 & 1.47 \\
\hline Single v married & 0.82 & 0.64 & 1.06 \\
\hline Hispanic v Non-Hispanic & 1.04 & 0.55 & 1.96 \\
\hline Rural v Urban & 1.06 & 0.76 & 1.91 \\
\hline$\geq \$ 4000 \mathrm{v}<\$ 35000$ & 0.82 & 0.36 & 1.48 \\
\hline$\geq \$ 46000 \mathrm{v}$ & 1.15 & 0.90 & \\
\hline$\$ 35001-\$ 45999$ & & & \\
\hline
\end{tabular}

Asterisk indicates $P$ value $<0.05$.

Table 10. ORs based on the last 15 years of data for melanoma

\begin{tabular}{|c|c|c|c|}
\hline \multicolumn{2}{|c|}{$\begin{array}{c}\text { Odds ratio estimates for advanced melanoma, 2000-2015 } \\
\mathrm{N}=135\end{array} \mathrm{765, \textrm {n } = 1 0 7 7}$} \\
\hline Variables & \multirow{2}{*}{ Odds ratio } & \multicolumn{2}{c|}{$95 \%$ Confidence level } \\
\cline { 3 - 4 } & & Lower boundary & Lower boundary \\
\hline Insured v uninsured & 1.51 & 0.71 & 3.20 \\
\hline White v Black & 2.53 & 0.81 & 7.87 \\
\hline Other v White & 0.37 & 0.07 & 2.07 \\
\hline Female v male & 1.16 & 0.90 & 1.50 \\
\hline Single v married & 0.81 & 0.63 & 1.06 \\
\hline Hispanic v Non-Hispanic & 1.12 & 0.59 & 2.13 \\
\hline Rural v Urban & 1.06 & 0.75 & 1.49 \\
\hline$\geq \$ 4000 \mathrm{v}<\$ 35000$ & 0.85 & 0.37 & 1.97 \\
\hline$\geq \$ 46000 \mathrm{v}$ & 1.15 & 0.89 & 1.48 \\
\hline$\$ 35001-\$ 45999$ & & & \\
\hline
\end{tabular}




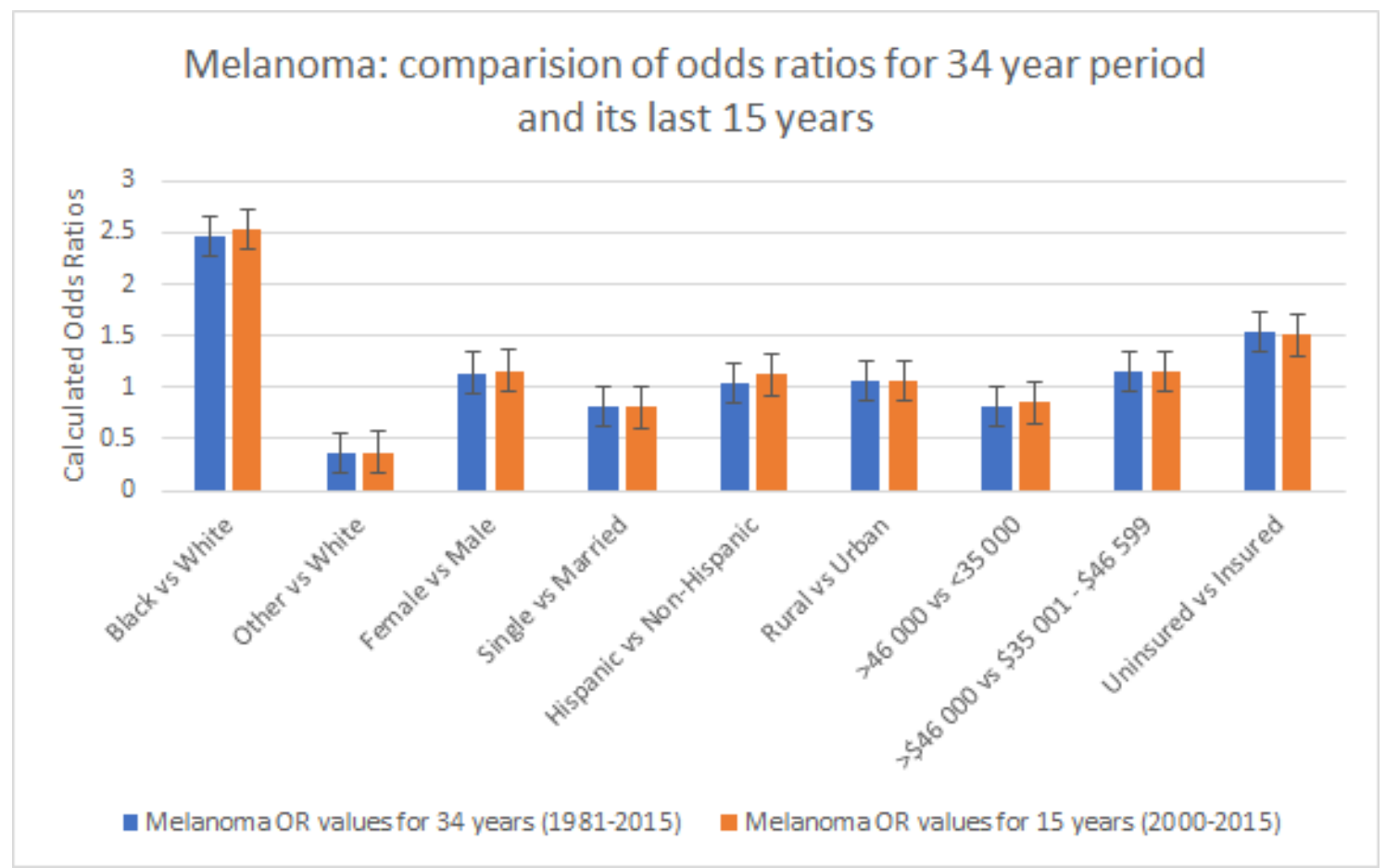

Figure 5. Comparison of ORs over 34 years (1981-2015, blue) versus 15 years (2000-2015, orange) data for melanoma. X-axis indicating the socioeconomic factor, and the $\mathrm{Y}$-axis indicating the OR value. As seen above, there have not been significant changes in ORs for each socioeconomic factor analyzed when comparing 2000-2015 to 1981-2015.

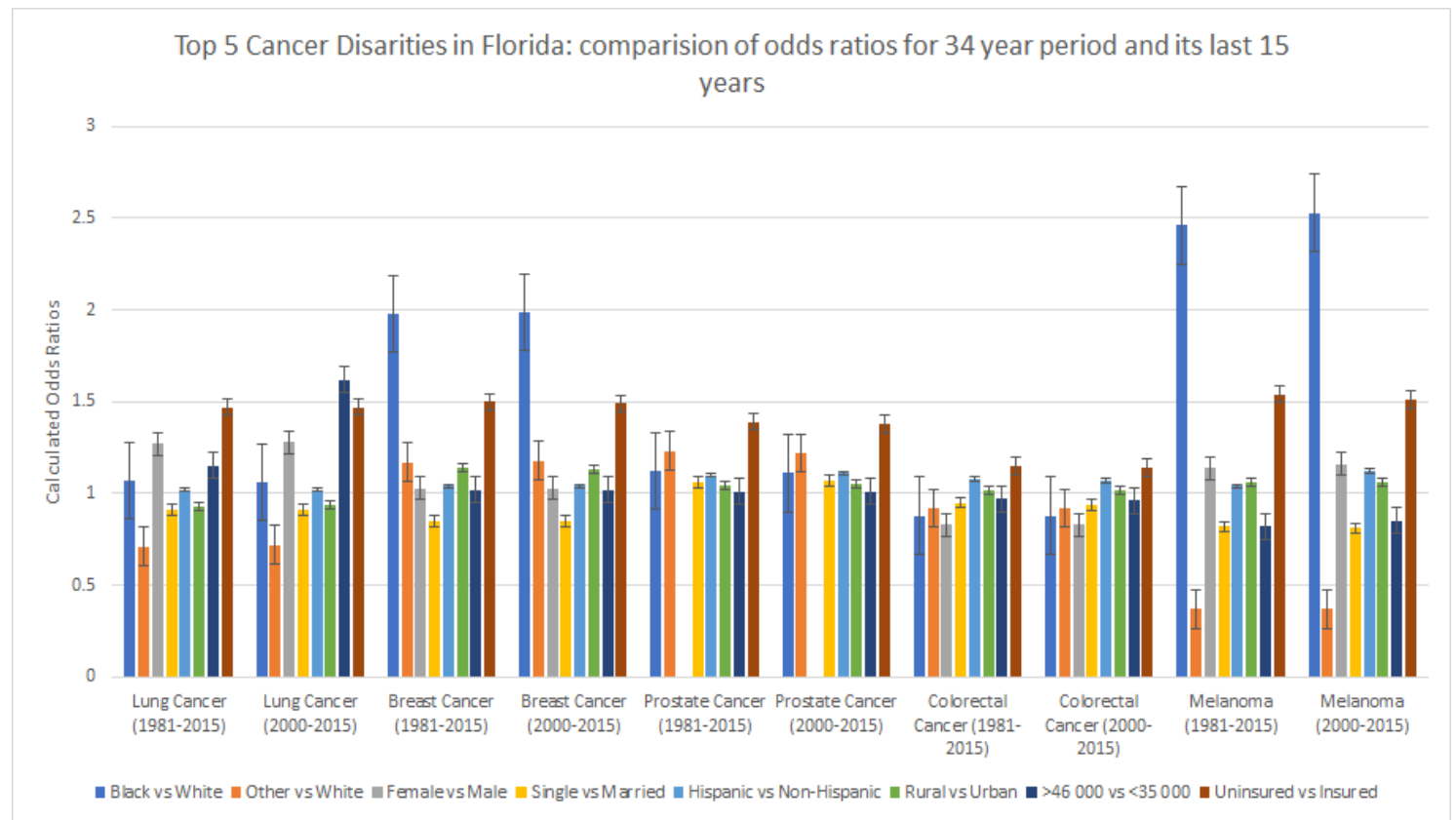

Figure 6. Side by side comparison of ORs over 34 years (1981-2015) versus 15 years (2000-2015) data for all five cancers. X-axis indicating the 34 year span from 1981-2015 or 15 year span from 2000-2015 for each cancer type, and the Y-axis indicating the OR value. As seen above, there have not been significant changes in ORs for each socioeconomic factor analyzed when comparing 2000-2015 to 1981-2015. 
Table 11. Summary of socioeconomic factors influencing risk of having a high-grade cancer at time of first diagnosis. Each factor listed was found to be statistically significant

\begin{tabular}{|c|c|}
\hline \multicolumn{2}{|c|}{ Summary of Findings } \\
\hline Cancer Type & Factors Affecting Risk of High-Grade Cancer at First Diagnosis \\
\hline Lung & Insurance Status \\
& Ethnicity \\
& Gender \\
& Marital Status \\
& Rural vs Urban \\
& Median County Income \\
\hline & Insurance Status \\
& Race \\
& Ethnicity \\
& Gender \\
& Marital Status \\
& Rural vs Urban \\
& Median County Income \\
\hline & Insurance Status \\
& Race \\
& Ethnicity \\
& Marital Status \\
\hline Colorectal & Insurance Status \\
& Race \\
& Ethnicity \\
& Gender \\
& Marital Status \\
& Median County Income \\
\hline
\end{tabular}

\section{Discussion}

Established in 2004, the state of Florida created the Office of Minority Health and Health Equity (OMHHE) with the goal of improving health inequities faced by Florida's minority population. According to the OMHHE, minority populations in Florida have worse health outcomes compared to Florida's general population in many health conditions, including cancer [20]. Florida currently has outreach programs, such as a mobile mammography van, that have been successful in increasing the annual number of uninsured patients receiving breast cancer screening, but even these types of outreach programs have their limitations [21].

Although programs have been implemented to help improve cancer screening, there still appears to be a disconnect between these efforts and the socioeconomic disparity gap within Florida. As this study suggests, further efforts are still needed to close these gaps. When comparing the ORs for breast cancer, lung cancer, prostate cancer, colorectal cancer, and melanoma from 1981-2015 versus the data from the last 15 years, there does not appear to be a meaningful decrease in the health disparities examined. In fact, there are certain health disparity gaps that appear to have worsened over the prior 15 years compared to the 34 -year data. For example, the odds of being diagnosed with advanced lung cancer based on income have increased when comparing the 2000-2015 data to the 1981-2015 data $(\mathrm{OR}=1.62 ; \mathrm{OR}=1.1 .5)$. All of the cancer types examined in this study did not qualitatively appear to show any improvement in health disparity gaps. It is important to note that intergroup statistical analysis was not directly carried out between the 34-year and 15-year data as a whole for each respective cancer. Directly comparing these two sets of data for breast cancer, lung cancer, prostate cancer, colorectal cancer, and melanoma would be a point of emphasis in future studies.

Specific goals for disparity gap improvement could focus on the largest gaps identified in the cancers studied. For lung cancer, the greatest disparity was found to be related to income status $(\mathrm{OR}=1.15$ at 34 years vs $\mathrm{OR}=$ 1.62 at 15 years). Race was the most considerable disparity for breast cancer $(\mathrm{OR}=1.98$ at 34 years vs $\mathrm{OR}=$ 1.99 at 15 years) and melanoma of the skin $(\mathrm{OR}=2.46$ at 34 years vs $\mathrm{OR}=2.53$ at 15 years); this suggests that racial disparities have not changed drastically within the last 15 years. Insurance status was the most prominent gap for both prostate cancer $(\mathrm{OR}=1.38$ at 34 years vs $\mathrm{OR}$ $=1.39$ at 15 years $)$ and colorectal cancer $(\mathrm{OR}=1.15$ at 34 years vs $\mathrm{OR}=1.14$ at 15 years).

In addition, it appears that some socioeconomic determinants consistently affect the grade of cancer at first diagnosis, regardless of the time interval that was analyzed (Table 11). Insurance status, ethnicity, and marital status all appear to affect the grade of cancer at first diagnosis for each cancer type, with the exception of melanoma. Analyzing the commonality underlying these consistent factors affecting Florida's minority population is important for directing future interventions, regardless 
of the health condition. Prior studies have noted that minority populations have multiple financial, cultural, and logistical barriers to receiving care [22]. However, each community appears to have its own specific barriers and a one-size-fits-all approach may be difficult to achieve.

All in all, it is difficult to determine from this datum alone the causes that contribute to the perpetuation of these disparities. In truth, they may be the result of multiple known concerns, including lack of insurance coverage, inability to reach underserved populations, program financial constraints, patient lack of knowledge about preventative programs, etc. Several studies have attempted to identify barriers for cancer screenings and resulted in similar findings. One study in particular looked at barriers for colorectal screenings among Hispanic women and found that $73 \%$ of women misidentified colorectal cancer for prostate or breast cancer; a small proportion were aware of colonoscopies but were unaware of its use as a screening tool [23]. In addition to patient lack of knowledge, a few studies noted 'emotional barriers' that exist for cancer screenings as well, involving embarrassment, anxiety, and fear of the results [22, 23]. Existing barriers may also lie with our healthcare providers, as feelings of cultural incompetence and uncertainty of the needs of minority populations have been noted as areas of concern [22]. Additional areas for improvement appear to lie within provider knowledge of programs, screening protocols, and insurance coverage; a recent study examining national barriers to lung cancer screening identified that providers had difficulty with eligibility criteria for screening, inadequate time to pursue shared decision making with patients, and management of screening results [24].

In order to investigate the primary factors involved, it may be prudent to consider a community-based participatory research (CBPR) approach, in which the scientific community and community members discuss the concerns and together identify feasible solutions that can be implemented within the community. This process often involves discussing issues that the community believes are important, bringing together people with different skill sets, discussing the goals of researchers, and finding ways to incorporate research findings into meaningful interventions [25]. Multiple studies indicate that CBPR improves the ability to apply cultural humility when addressing cancer screenings, reduces language barriers, precludes the implementation of a one-sided agenda by the scientific community, and allows the development of trust between researchers and underserved populations [25]. Oftentimes, using CBPR helps researchers understand why certain health disparities exist, even though interventions have been targeted to improve those disparities. For example, one study discovered that gaining community trust and participation in an intervention was most effective when having family members or other people within a person's close social network recommends a health intervention [25].

\subsection{Future Direction}

Overall, there are several significant gaps of care that have been identified for these top five cancers, with more individuals that are of lower socioeconomic status, Black, uninsured, and Hispanic diagnosed with more advanced forms of these cancers. Each major gap for the cancers considered has been evaluated; now that this information is known, it needs to be addressed. Future programs can be aimed at reducing the health disparities with the largest gaps for each cancer subgroup. For example, future programs can focus on reducing disparities due to income for lung cancer, racial gaps for breast cancer and melanoma, and insurance status for colorectal and prostate cancer. Future studies can focus on exploring race-specific barriers to care, in addition to specific factors influencing these numbers, i.e. transportation concerns, access issues, lack of knowledge of programs currently established, insurance status, and the cost involved.

However, when determining how to address these continuing health disparities, it will be vital to incorporate CBPR into the investigation process. As noted earlier, interventions to help with cancer screening have been implemented to improve cancer outcomes for minority populations, but it is imperative to work with these communities to identify exactly why current efforts are not making as large of an impact on the cancer grade at first diagnosis. We propose that future studies begin at the Florida county level and bring together stakeholders from the community to help identify the specific aspects that are contributing to the current cancer health care disparity. Topics to discuss would include cultural beliefs, knowledge gaps, stigma towards cancer and screenings, perceived threat of cancer, logistical barriers, building trust within the community, and learning what outcomes the community itself values. Once researchers understand the needs of the community at the county level, the same principles can be applied to the state level to identify common themes and more effectively aim interventions to close the existing health disparities in the severity of cancer at first diagnosis.

\section{Limitations}

This study contains certain limitations. Firstly, this study used county level data to determine the differences in rates of advanced stage cancer at initial diagnosis across various social factors in the analysis. To avoid an ecological fallacy, the aggregated county level data should not be used to draw conclusions at the individual level. Further investigation using data at the individual level would be needed for a more appropriate interpretation. 
Secondly, this study used the county in which the individual was diagnosed, not the zip code of residence for each individual case of cancer. If individuals travelled across county lines to seek a diagnosis, those individual cancer cases would have been included at the county of diagnosis, not the county where they resided. Thirdly, this study did not have individual level data on household income. As a result, county level estimates for income were used in this study. Lastly, this study was not able to acquire age from the provided FCDS data set and should be examined in future studies.

\section{Conclusions}

Although many interventions over the past 15 years have been aimed at reducing disparities in cancer outcomes, it appears that social determinants such as race, ethnicity, insurance, income, and geographic location still play a significant role as predictors of advanced stage of cancer at initial diagnosis for Florida natives. Health disparities continue to affect particular populations, and there has not been a significant reduction in the cancer burden among certain races and uninsured individuals. Future investigations via a community-based participatory research approach are needed to explore methods in reducing cancer burden among social determinants, in addition to more targeted population-based public health programs to establish health equity in our citizens.

\section{Acknowledgements}

The authors would like to thank the Florida Department of Health for the use of their cancer registry.

Authors' contributions were equal, and Mary Parianos is a joint-first author with Matthew Sasaki.

No declared conflicts of interest or funding.

\section{REFERENCES}

[1] American Cancer Society, "Cancer Facts \& Figures 2019," American Cancer Society,

https://www.cancer.org/content/dam/cancer-org/research/ca ncer-facts-and-statistics/annual-cancer-facts-and-figures/20 19/cancer-facts-and-figures-2019.pdf (accessed May 2020).

[2] Islami, F., Miller, K. D., Siegel, R. L., et al, "National and State Estimates of Lost Earnings From Cancer Deaths in the United States.” JAMA Oncology, vol. 5, no. 9, pp. e191460, 2019. DOI: 10.1001/jamaoncol.2019.1460

[3] Xu, J. Q., Murphy, S. L., Kochanek, K. D., Bastian, B., \& Arias, E., "Deaths: Final data for 2016," National Vital Statistics Reports, vol. 67, pp1-75, 2018, https://www.cdc.g ov/nchs/data/nvsr/nvsr67/nvsr67_05.pdf (accessed May 2020).
[4] Kish, J. K., Yu, M., Percy-Laurry, A., \& Altekruse, S. F., "Racial and ethnic disparities in cancer survival by neighborhood socioeconomic status in Surveillance, Epidemiology, and End Results (SEER) Registries,” Journal of the National Cancer Institute Monographs, vol. 2014, no. 49, pp. 236-243, 2014. DOI: 10.1093/jncimonographs/lgu0 20

[5] National Cancer Institute, "Cancer Disparities," 2019, https://www.cancer.gov/about-cancer/understanding/dispari ties (accessed July 2020).

[6] Florida Cancer Data System, "Table 3. Number of New Cancer Cases by Sex, Race, and Age Group, Florida, 2014," 2014,https://fcds.med.miami.edu/downloads/FloridaAnnual CancerReport/2014/Table_No_T3_(2014).pdf_ (accessed May 2020).

[7] Torre L. A., Bray, F., Siegel, R. L., Ferlay, J., Lortet-Tieulent, J., \& Jemal, A., "Global cancer statistics, 2012," A Cancer Journal for Clinicians, vol. 65, no. 2, pp. 87-108, 2015. DOI: 10.3322/caac.21262

[8] DeSantis, C. E., Ma, J., Goding Sauer, A., Newman, L. A., \& Jemal, A., "Breast cancer statistics, 2017, racial disparity in mortality by state," A Cancer Journal for Clinicians, vol. 67, no. 6, pp. 439-448, 2017. DOI: $10.3322 /$ caac. 21412

[9] Pinheiro, P. S., Callahan, K. E., Koru-Sengul, T., et al, "Risk of Cancer Death among White, Black, and Hispanic Populations in South Florida," Preventing Chronic Disease, vol. 16, pp. 180529, 2019. DOI: 10.5888/pcd16.180529

[10] Florida Cancer Data System, "Table 17. Number of Cancer Deaths by Sex, Race and Age Group, Florida, 2014,” 2014, https://fcds.med.miami.edu/downloads/FloridaAnnualCanc erReport/2014/Table_No_T17_(2014).pdf_ (accessed May 2020).

[11] Siegel, R. L., Miller, K. D., \& Jemal, A, "Cancer Statistics, 2017” A Cancer Journal for Clinicians, vol. 67, no. 1, pp. 7-30, 2017. DOI: $10.3322 /$ caac. 21387

[12] Siegel, R. L., Miller, K. D., \& Jemal, A, "Cancer Statistics, 2018," A Cancer Journal for Clinicians, vol. 68, no. 1, pp. 7-30, 2018. DOI: $10.3322 /$ caac. 21442

[13] Bahls, C, "Health policy brief: achieving equity in health," Health Affairs, 2011, https://www.healthaffairs.org/do/10.1 377/hpb20111006.957918/full/healthpolicybrief_53.pdf (accessed June 2020).

[14] Centers for Disease Control and Prevention and National Cancer Institute, "Leading Cancer Cases and Deaths, All Races/Ethnicities, Male and Female, 2017," U.S. Cancer Statistics, http://www.cdc.gov/cancer/dataviz (accessed May 2020).

[15] Florida Cancer Data System, "Table 17: Number of Cancer Deaths by Sex, Race and Age Group, Florida, 2015,” 2015, https://fcds.med.miami.edu/downloads/FloridaAnnualCanc erReport/2015/Table_No_T17_(2015).pdf (accessed May 2020).

[16] American Cancer Society, "Global Cancer Facts \& Figures 4th Edition," 2018, https://www.cancer.org/content/dam/ca ncer-org/research/cancer-facts-and-statistics/global-cancerfacts-and-figures/global-cancer-facts-and-figures-4th-editio n.pdf (accessed May 2020). 
[17] World Health Organization, International Classification of Diseases for Oncology (3rd ed.), 2013.https://apps.who.int/ iris/bitstream/handle/10665/96612/9789241548496_eng.pd f;jsessionid=E939723C0CF7BF524ABC30489A2B05BF?u $\mathrm{a}=1$ ? sequence $=1$ (accessed May 2020).

[18] Rahman, S. M. M., Dignan, M. B., \& Shelton, B. J., "Factors influencing adherence to guidelines for screening mammography among women aged 40 years and older," Ethnicity and Disease, vol. 13, no. 4, pp. 477-484, 2003. https://www.ncbi.nlm.nih.gov/pmc/articles/PMC2848385/

[19] Rahman, S. M. M., Dignan, M. B., \& Shelton, B. J., “A Theory-Based Model for Predicting Adherence to Guidelines for Screening Mammography among Women Age 40 and Older," Journal of Cancer Prevention, vol. 2, no. 3, pp. 169-179, 2005. https://www.ncbi.nlm.nih.gov/pmc/ar ticles/PMC2613295/

[20] Florida Department of Health, "Minority Health and Health Equity," http://www.floridahealth.gov/programs-and-services/minori ty-health/index.html (accessed July 2020).

[21] Centers for Disease Control and Prevention, "Bringing
Mammograms to Uninsured Women in Florida," 2019, https://www.cdc.gov/cancer/nbccedp/success/mammogram s-in-florida.htm (accessed July 2020).

[22] Baird, J., Yogeswaran, G., Oni, G., Wilson, E. E., "What can be done to encourage women from Black, Asian and minority ethnic backgrounds to attend breast screening? A qualitative synthesis of barriers and facilitators," Public Health, vol. 190, pp. 152-159, 2021. DOI: 10.1016/j.puhe.2020.10.013

[23] Byrd, T. L., Calderon-Mora, J., Salaiz, R., Shokar, N. K., "Barriers and Facilitators to Colorectal Cancer Screening Within a Hispanic Population," His Health Care Int, vol. 17, no. 1, pp. 23-29, 2019. DOI: 10.1177/1540415318818982

[24] Wang, G. X., Baggett, T. P., Pandharipande, P. V., et. al, "Barriers to Lung Cancer Screening Engagement from the Patient and Provider Perspective," Radiology, vol. 290, no. 2, pp. 278-287, 2019. DOI: 10.1148/radiol.2018180212

[25] Xin, H., "Community-based Participatory Research (CBPR) and Refugees' Health Studies: What's Working and What's Not Working," Univers J Public Health, vol. 7, no. 3, pp. 103-109, 2019. DOI: 10.13189/ujph.2019.070303 